\title{
CORVI, TIPOLOGÍAS DE VIVIENDAS RACIONALIZADAS: UN EJERCICIO DE ESTANDARIZACIÓN
}

CORVI, tipologias de habitação racionalizadas:

Um exercício de padronização

CORVI, rationalized housing typologies:

An exercise in standardization

Jorge Eduardo Vergara Vidal

Profesor Asociado, Escuela de Sociología, Facultad de Ciencias Sociales. Universidad de Valparaíso.

Valparaíso, Chile.

jorge.vergaravi@uv.cl

https://orcid.org/0000-0002-7712-4090

\section{Denisse Dintrans Bauer}

Asistente de Investigación. Escuela de Sociología,

Facultad de Ciencias Sociales. Universidad de

Valparaíso. Valparaíso, Chile.

denissedintrans@gmail.com

https://orcid.org/0000-0001-6379-3579

\section{Daniela Álvarez Campos}

Académica Escuela de Arquitectura. Universidad de Santiago. Santiago, Chile.

daniela.alvarez@usach.cl

https://orcid.org/0000-0001-5290-0041

\section{Diego Asenjo Muñoz}

Coordinador de Proyecto, Dirección de Infraestructura. Corporación Municipal de Renca. Santiago, Chile.

dmasenjo@uc.cl

https://orcid.org/0000-0003-2136-966X
Artículo producto del proyecto "Obras de Especulación. Prototipos y Tipologías diseñadas y construidas por CORVI entre 1966 y 1972", FONDART N ${ }^{\circ} 547745$, financiado por el Fondo Nacional de Desarrollo Cultural y las Artes, Línea de Investigación en Arquitectura.

Tipologías de Viviendas diseñadas en CORVI entre 1966 y 1971 .

Fuente: Elaboración propia a partir de los datos contenidos en Tipologías de viviendas racionalizadas 19661972 (CORVI, 1972).

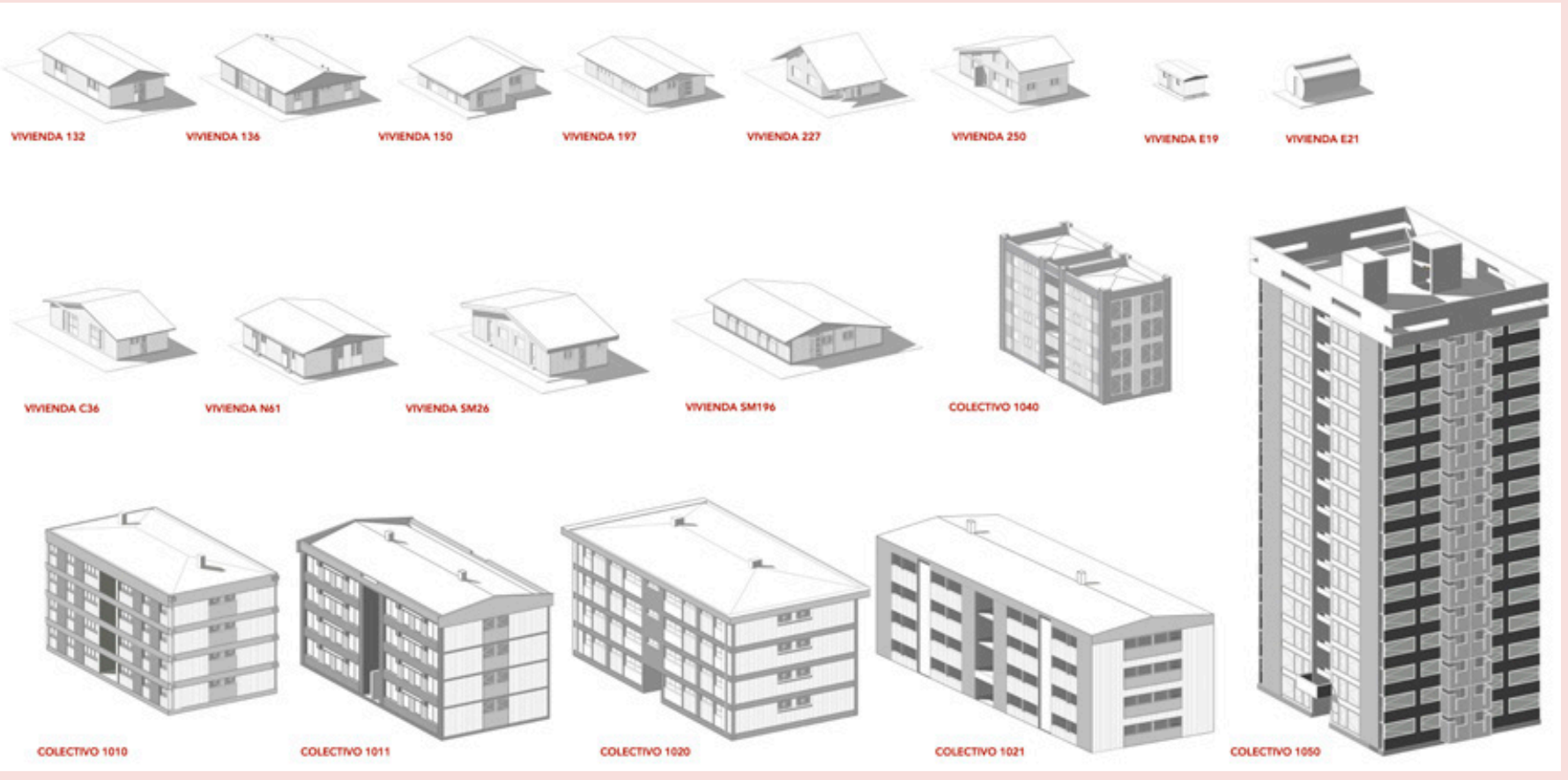




\title{
RESUMEN
}

Las viviendas de interés social diseñadas por los equipos de la Corporación de la Vivienda (CORVI) constituyen una presencia material de enorme influencia dentro de la sociedad chilena y dentro de la comunidad de prácticas de la arquitectura. El presente trabajo observa la labor realizada por dichos equipos a partir del análisis de la información contenida en el documento Tipologías de viviendas racionalizadas 1966-1972, de CORVI. Éste entrega datos sobre las formas, dimensiones, materialidades y programas de dieciocho tipologías de viviendas elaboradas por los equipos de diseño entre 1966 y 1971 . No todos estos prototipos llegaron a ser construidos, pero su conjunto da cuenta de cómo se concibió llevar a lo concreto la idea de racionalización de las viviendas de interés social, y de cómo ello devino en un ejercicio de estandarización, basado en tipologías, del cual es posible aprender tanto las formas de orden y disposición de lo cotidiano que propone, como la flexibilidad interpretativa que utiliza en su comunicación.

Palabras Clave: Tipologías, vivienda, prototipo, estandarización, CORVI

\section{RESUMO}

As habitações de interesse social projetadas pelas equipes da Corporación de la Vivienda (CORVI) constituem uma presença material de enorme influência na sociedade chilena e na comunidade de práticas arquitetônicas. O presente artigo observa o trabalho destas equipes mediante a análise das informações contidas no documento do CORVI "Tipologías de viviendas racionalizadas 1966-1972" (Tipologias de habitações racionalizadas 1966-1972), que fornece dados sobre as formas, dimensões, materialidades e programas de dezoito tipologias habitacionais elaboradas pelas equipes de design entre 1966 e 1971. Nem todos estes protótipos foram construídos, mas o conjunto mostra como a ideia da racionalização da habitação de interesse social foi concebida e como se tornou um exercício de padronização, baseado em tipologias, a partir do qual é possível aprender tanto as formas de ordem e disposição da vida cotidiana propostas, como também a flexibilidade interpretativa utilizada em sua comunicação.

Palavras-Chave: Tipologias, habitação, protótipo, padronização, CORVI

\begin{abstract}
The social housing designed by the teams of the Corporación de la Vivienda (CORVI) constitutes a material presence of enormous influence within Chilean society and within the community of architectural practices. This paper observes the work of these teams, by analyzing the information contained in the CORVI document called "Tipologías de viviendas racionalizadas 1966-1972 (Rationalized Housing Typologies 1966-1972)", which provides data on the shapes, dimensions, materials, and programs of eighteen housing typologies developed by the design teams between 1966 and 1971. Not all of these prototypes were built, but as a whole, it shows how the idea of social housing rationalization was conceived, and how it became an exercise in standardization, based on typologies, from which it is possible to learn both the forms of order and layout of everyday life that they propose, along with the interpretative flexibility used in their communication.
\end{abstract}

Keywords: Typologies, housing, prototype, standardization, CORVI 


\section{INTRODUCCIÓN}

Los estándares son cosas invisibles, sostenía Susan Leigh Star (2002), una de las pioneras en su estudio dentro de la sociología, pero están detrás de casi todo lo que nos rodea. Si invertimos el modo en que vemos las cosas, es posible notar como este tipo de objetos sostienen los contenidos performativos de todas las formas materiales que nos acompañan. Esto otorga a la estandarización un rol central en la vida social y cultura de la modernidad, no solo como explicación a la similitud y replicabilidad de sus soluciones objetuales, sino también como una forma de coordinación en que las prácticas materiales permiten especular el futuro (Esguerra, 2019; Hölscher, 2019). Los mundos materiales de la modernidad, sus mundos industriales y urbanos fueron construidos con estándares incrustados en ellos, como una forma semiótica que permite pensar en y con ellos (Galaz, 2019; Law y Mol, 2020).

Los procesos de estandarización, afirman Lampland y Star (2009), surgen de la necesidad de contar con acuerdos técnicos que contribuyan a agilizar los procedimientos, regular acciones, obtener resultados específicos o evitar daños. Están relacionados con la cuantificación, el modelado formal y la extracción, reutilización y clasificación de datos; expresan la organización de acuerdos técnicos sobre el trabajo, tareas y condiciones, que requieren ser replicados para obtener resultados cuantitativa y formalmente similares. Los estándares permiten que los acuerdos sobre el trabajo y sus resultados se desplacen objetualmente en el tiempo y en el espacio, replicándose en distintas realidades.

Si el trabajo es interacción (Hughes, 1989), los procesos de estandarización que posibilitan relocalizar el trabajo en situaciones diferentes y distantes, son una suerte de forma de interacción a distancia (Latour, 1987). En este sentido, una de las características de los estándares es que consideran diversos grados de delegación, de manera que, a pesar de normativizar prácticas materiales, son flexibles interpretativamente; por ello Star (2002) plantea que son intensamente locales y afectan a comunidades muy específicas en contextos muy específicos, independiente de los rangos globales que puede tener su alcance.

El presente artículo analiza el documento Tipologías de viviendas racionalizadas 1966-1972 como un caso que da cuenta de cómo los equipos de diseño proyectual de la Corporación de la Vivienda (CORVI) buscaron acotar las interacciones involucradas en el trabajo de selección, construcción y habitación de viviendas de interés social, por medio de la racionalización de sus materialidades, programas y tipos. Estos equipos siguieron las orientaciones que el arquitecto HéctorValdés, primero, y del arquitecto Hiram Quiroga, posteriormente, e imprimieron a las políticas de vivienda desde la Vicepresidencia ejecutiva de la Corporación (Sepúlveda y Carrasco, 1991; Gámez, 1999). No todos los diseños elaborados como tipologías e incluidos en el texto antes citado fueron finalmente construidos, pero 
claramente su sentido era orientar tanto la producción de viviendas como el posterior habitar de éstas y la socialidad que emergía de sus conjuntos.

Este trabajo aborda el documento señalado como la respuesta a un problema que venía "desde el periodo 1954-60, [donde] el diseño de las viviendas que era necesario renovar para políticas masivas, se confió al sector privado a través de concursos públicos. Ello trajo consigo una renovación e incorporación de criterios urbanísticos más contemporáneos a la acción habitacional, y paralelamente, un deterioro de los equipos técnicos. En el sexenio 64-70 se dieron algunos pasos para corregir la anarquía de tipos de vivienda y se buscó una racionalización de ellos, como la vivienda 132, en extensión y el bloque 1020, en altura" (Quiroga, 1972, p. 42). En ese contexto, los equipos de diseño de la CORVI elaboraron prototipos considerando como insumo el conjunto de la obra anteriormente construida hacia 1966.

El primer resultado de este ejercicio de diseño fueron siete prototipos que correspondían a viviendas en extensión (cinco) y colectiva en altura (dos), que explican gran parte de la vivienda construida en los gobiernos de Eduardo Frei y de Salvador Allende (CORVI 1969; 1972a), a pesar de tener signos políticos distintos. Hacia 197 I los prototipos originales fueron revisitados; proceso que originó otros cuatro tipos de vivienda extendida, cuatro nuevas versiones de colectivos en altura, incluido un edificio de dieciséis pisos y dos tipos de viviendas de emergencia. De lo anterior da cuenta el documento Tipologías de viviendas racionalizadas 1966-1972, donde los diseños son presentados, indistintamente, como tipologías y como prototipos de vivienda, y elaborados bajo el signo de la racionalización, con el fin de replicación masiva y seriada.

Aunque habitualmente la obra CORVI era publicada en folletos de texto general, dato de producción y fotografías por la Oficina de Relaciones Públicas de CORVI (1969, 1972a), el conjunto de estos prototipos fueron publicados bajo la firma del Sub Departamento de Diseño, con información detallada sobre sus plantas, elevaciones, dimensiones, materialidades y equipos responsables, a escalas de I: 1000 y 1:2000, y sin otro texto más que una editorial del Jefe del Sub Departamento donde José Quintela asevera que este constituye "el testimonio arquitectónico del proceso de racionalización del Diseño de la Vivienda tipificada, para un uso repetitivo, serializado, a escala nacional" (CORVI, I972b). Todo lo anterior ayudó a definir al documento en cuestión como el corolario de un ejercicio de diseño en que se logró establecer parámetros similares para las formas, materialidades, dimensiones y programas de las viviendas, lo que da cuenta de un proceso de estandarización que además presenta un marco suficientemente flexible para su adecuación y replicabilidad en situaciones locales diferentes. 


\section{METODOLOGÍA}

\section{FORMA}

AS / Vol. 39. No59 / ENERO 2021 // ISSN impresa 07 I 6-2677 / ISSN digital 0719-6466

CORVI, TIPOLOGÍAS DE VIVIENDAS RACIONALIZADAS:

UN EJERCICIO DE ESTANDARIZACIÓN
Jorge Eduardo Vergara Vidal, Daniela Álvarez Campos, Denisse Dintrans Bauer y Diego Asenjo Muñoz
Para determinar el tipo de estandarización que caracteriza el ejercicio de diseño analizado, se sistematizó la información de cada prototipo de vivienda presente en Tipología de viviendas racionalizadas 1966-1972 (CORVI, 1972b). Esta información se agrupó en cuatro dimensiones: forma, materiales, dimensiones, programas; lo cual permitió verificar los modos en que los prototipos mantenían similitudes entre ellos y también los modos en que organizaban sus diferencias. A continuación, se exponen los resultados de cada una de las dimensiones señaladas y se proponen conclusiones sobre el tipo de estandarización de la vivienda que caracterizó la agenda de racionalización constructiva de CORVI.

Como se señalaba, Tipología de viviendas racionalizadas 1966 1972 reúne información sistemática sobre dieciocho prototipos de viviendas diseñados entre 1965 y 197।. Su origen corresponde a los departamentos de diseño de CORVI, cuya estructura fue variando entre los dos periodos señalados, aunque sus integrantes persistieron mayoritariamente durante ellos. Así, en el periodo 1964-1970, el departamento de diseño consideraba una división norte, centro y sur, siguiendo la división climática y geográfica que habitualmente se hace del país, lo que se traduce en el sentido "regionalizado" que proclaman los prototipos y que incide en las elecciones de las materialidades de cada uno [Tabla I]. Los equipos se unifican en el Sub Departamento de Diseño a partir de 1971 y la experiencia de producción de los prototipos 132, 136, 1010 y 1020, que se expandieron por todo el país, deja de lado la indicación regionalizada porque resulta irrelevante.

El arquitecto Rafael Moneo define "tipología" como "aquel concepto que describe un grupo de objetos caracterizados por tener la misma estructura formal" (1978, p. 190). En esos términos, el documento utiliza el vocablo "tipología" para indicar si el prototipo corresponde a una vivienda pareada, que generalmente corresponde a una vivienda en extensión [Figura I] o a un colectivo (bloque o edificio) aislado [Figura 2]. Las casas son pareadas o, mejor dicho, contienen dos unidades de vivienda pareadas. Los colectivos de vivienda son clasificados como "tipología aislada", aunque contienen unidades de vivienda pareadas, que comparten una misma pared.

En su introducción a Tipología de viviendas racionalizadas 1966 1972, José Quintela (1972) utiliza indistintamente los términos "tipologías" y "prototipos" para referirse a los dieciocho diseños, pero en el documento también se emplea el término "tipología" para indicar si se trata de una casa pareada o de un edificio aislado. Independiente de lo anterior, y siguiendo la definición de Moneo (1978), el documento ofrece cuatro conjuntos con similitudes estructurales internas: viviendas en extensión (casas), colectivos en altura (de cuatro y más pisos) y viviendas de emergencia (unidades 
Tabla 1

Datos generales sobre aspectos de

forma de prototipos de viviendas

racionalizadas. CORVI 1965-1972.

Fuente: Elaboración de autores a partir

de CORVI (1972b).

\begin{tabular}{|c|c|c|c|c|c|c|c|c|}
\hline \multirow{2}{*}{ Tipo } & \multirow{2}{*}{ Prototipo } & \multirow{2}{*}{$\begin{array}{l}\text { Año de } \\
\text { diseño }\end{array}$} & \multicolumn{6}{|c|}{ Generalidades } \\
\hline & & & Origen & Diseño & Utiliza & ión & $\begin{array}{c}\text { Sistema } \\
\text { constructivo }\end{array}$ & Tipología \\
\hline \multirow{6}{*}{$\begin{array}{l}\text { A. Viviendas } \\
\text { en Extensión } \\
\text { 1966-1970 }\end{array}$} & N 61 & 1967 & Depto Sur & Racionalizada & Regionalizada & Zona Norte & Tradicional & Pareada \\
\hline & 132 & 1966 & Depto Central & Racionalizada & Regionalizada & No indica & Tradicional & Pareada \\
\hline & 136 & 1966 & Depto Central & Racionalizada & Regionalizada & No indica & Tradicional & Pareada \\
\hline & sm-196 & 1966 & Depto Sur & Racionalizada & Regionalizada & Zona Sur & $\begin{array}{l}\text { Semi } \\
\text { Industrializada }\end{array}$ & Pareada \\
\hline & 197 SM & 1966 & Depto Sur & Racionalizada & Regionalizada & Zona Norte & $\begin{array}{l}\text { Semi } \\
\text { Industrializada }\end{array}$ & Pareada \\
\hline & 227 SM & 1966 & Depto Sur & Racionalizada & Regionalizada & Zona Sur & Tradicional & Pareada \\
\hline \multirow{4}{*}{$\begin{array}{l}\text { B. Viviendas } \\
\text { en Extensión } \\
1971-972\end{array}$} & C-36 & $\begin{array}{l}1970- \\
1971\end{array}$ & $\begin{array}{l}\text { Depto Diseño } \\
\text { Manuel Montt }\end{array}$ & Racionalizada & Regionalizada & $\begin{array}{l}\text { Zona Cen- } \\
\text { tral }\end{array}$ & Tradicional & Pareada \\
\hline & SM-36 & 1971 & Depto Sur & Racionalizada & Regionalizada & $\begin{array}{l}\text { Sin } \\
\text { Información }\end{array}$ & $\begin{array}{l}\text { Semi } \\
\text { Industrializada }\end{array}$ & Pareada \\
\hline & 150 & 1972 & $\begin{array}{l}\text { Sub Depto } \\
\text { Diseño }\end{array}$ & Racionalizada & Regionalizada & $\begin{array}{l}\text { Zona Cen- } \\
\text { tral }\end{array}$ & Tradicional & Pareada \\
\hline & 250 & 1972 & $\begin{array}{l}\text { Sub Depto } \\
\text { Diseño }\end{array}$ & Racionalizada & Regionalizada & $\begin{array}{l}\text { Zona Cen- } \\
\text { tral }\end{array}$ & Tradicional & Pareada \\
\hline \multirow{2}{*}{$\begin{array}{l}\text { C. Colectivos } \\
\text { en Altura - } \\
1966-1970\end{array}$} & 1010 & 1965 & $\begin{array}{l}\text { Departamento } \\
\text { de Estudio }\end{array}$ & Racionalizada & Regionalizada & Todo el país & Tradicional & Aislada \\
\hline & 1020 & 1965 & $\begin{array}{l}\text { Departamento } \\
\text { de Estudio }\end{array}$ & Racionalizada & Regionalizada & Todo el país & Tradicional & Aislada \\
\hline \multirow{4}{*}{$\begin{array}{l}\text { D. Colectivos } \\
\text { en Altura - } \\
1971-1972\end{array}$} & 1011 & 1972 & $\begin{array}{l}\text { Sub Depto } \\
\text { Diseño }\end{array}$ & Racionalizada & Regionalizada & Todo el país & Tradicional & Aislada \\
\hline & 1021 & 1971 & $\begin{array}{l}\text { Sub Depto } \\
\text { Diseño }\end{array}$ & Racionalizada & Regionalizada & Todo el país & Tradicional & Aislada \\
\hline & 1040 & 1972 & $\begin{array}{l}\text { Sub Depto } \\
\text { Diseño }\end{array}$ & Racionalizada & Regionalizada & $\begin{array}{l}\text { Zona } \\
\text { Central }\end{array}$ & Tradicional & $\begin{array}{l}\text { Aislada/ } \\
\text { Pareada }\end{array}$ \\
\hline & 1050 & 1972 & $\begin{array}{l}\text { Sub Depto } \\
\text { Diseño }\end{array}$ & Racionalizada & Regionalizada & $\begin{array}{l}\text { Zona } \\
\text { Central }\end{array}$ & Tradicional & $\begin{array}{l}\text { Aislada/ } \\
\text { Pareada }\end{array}$ \\
\hline \multirow{2}{*}{$\begin{array}{l}\text { E. Viviendas } \\
\text { de } \\
\text { Emergencia }\end{array}$} & e19 & $\begin{array}{l}\text { No } \\
\text { indica }\end{array}$ & - & - & - & - & - & - \\
\hline & e21 & $\begin{array}{l}\text { No } \\
\text { indica }\end{array}$ & - & - & - & - & - & - \\
\hline
\end{tabular}


Figura 1

Tipología de

Viviendas en

Extensión diseñadas

en CORVI entre 1966

en CORVI

Fuente: CORVI

(1972b, p. A1-E2).
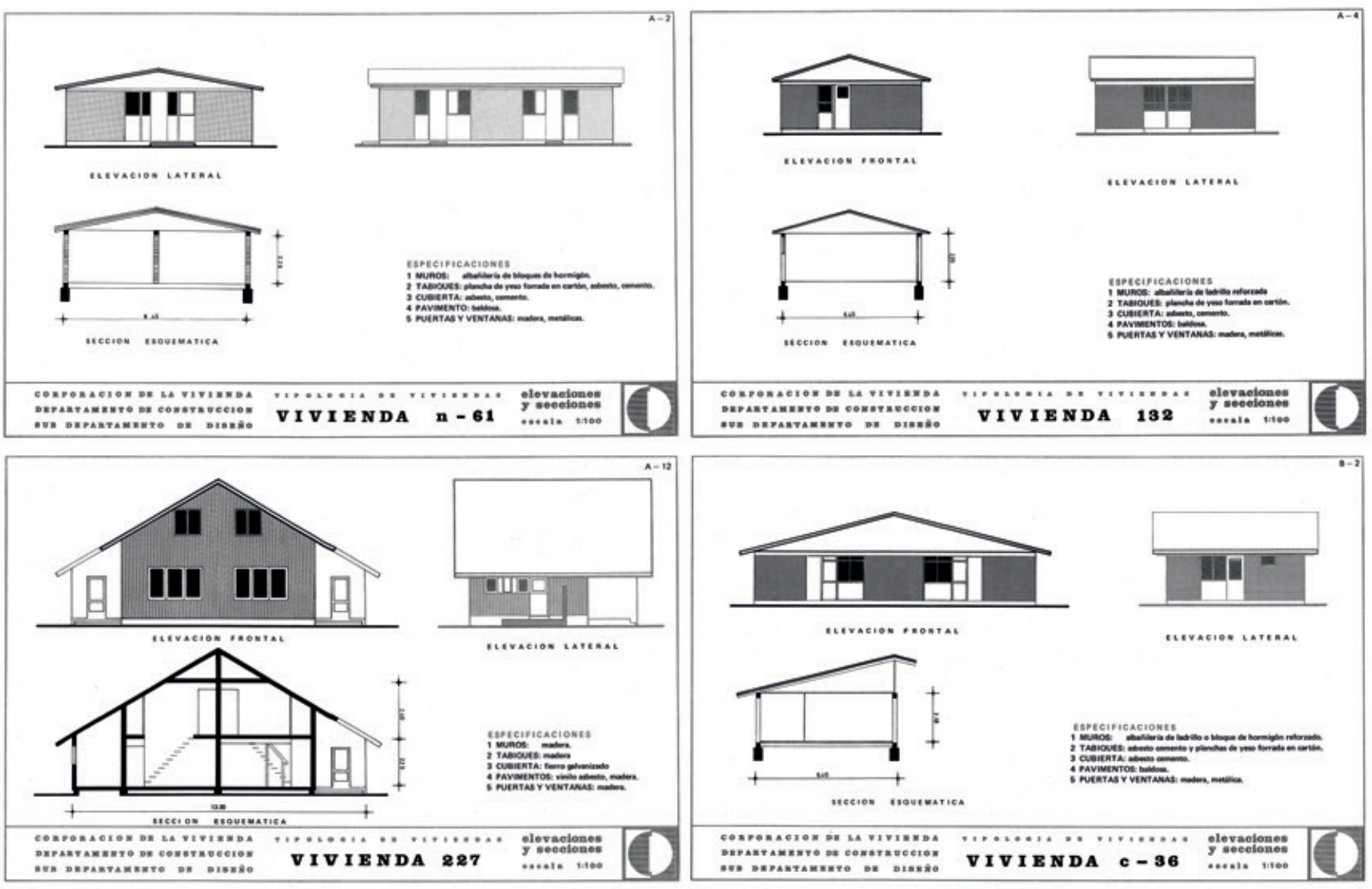

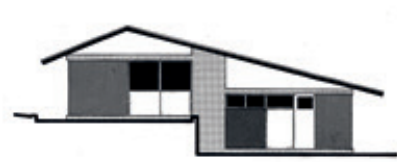

meracion atens

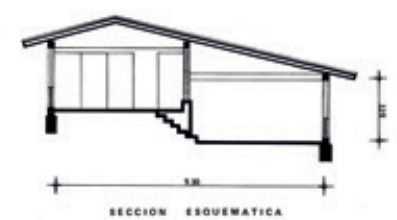

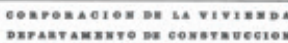

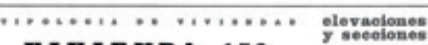

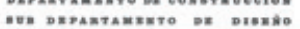

IsPeCHicaciones

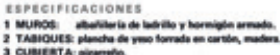

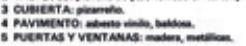

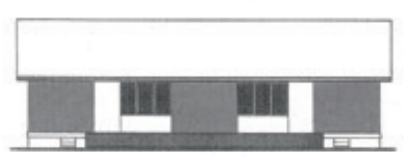

curnerean mostas
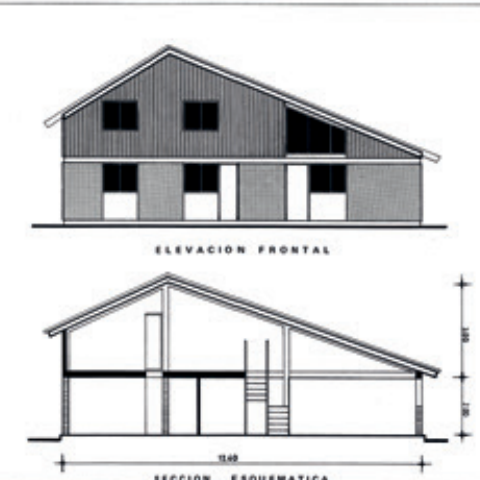

tover

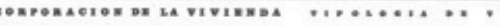

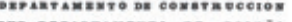

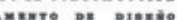

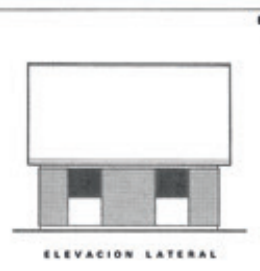

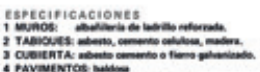

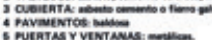


con un solo programa). En este marco, cabe señalar que el colectivo 1050, que corresponde a un edificio residencial de 16 pisos, debiese ser considerado como una forma diferente a los colectivos en altura, que corresponden a bloques de vivienda de cuatro pisos. El hecho de que ambas formas estén consideradas dentro de la misma tipología da cuenta de que su similitud estructural es también un vínculo epistemológico: ambas son parte del mismo ejercicio de estandarización de la vivienda colectiva y de una similar reflexión proyectual.
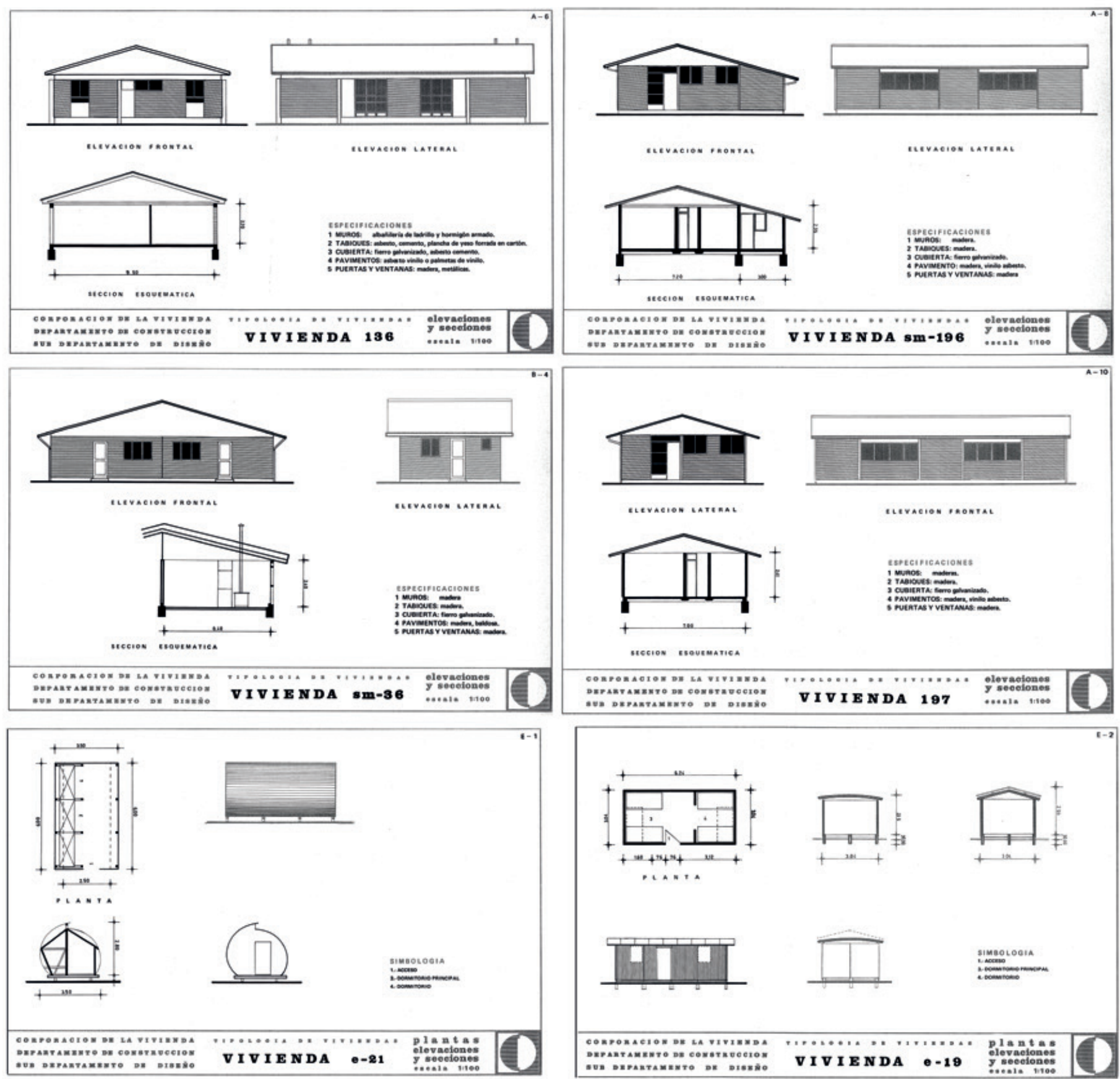

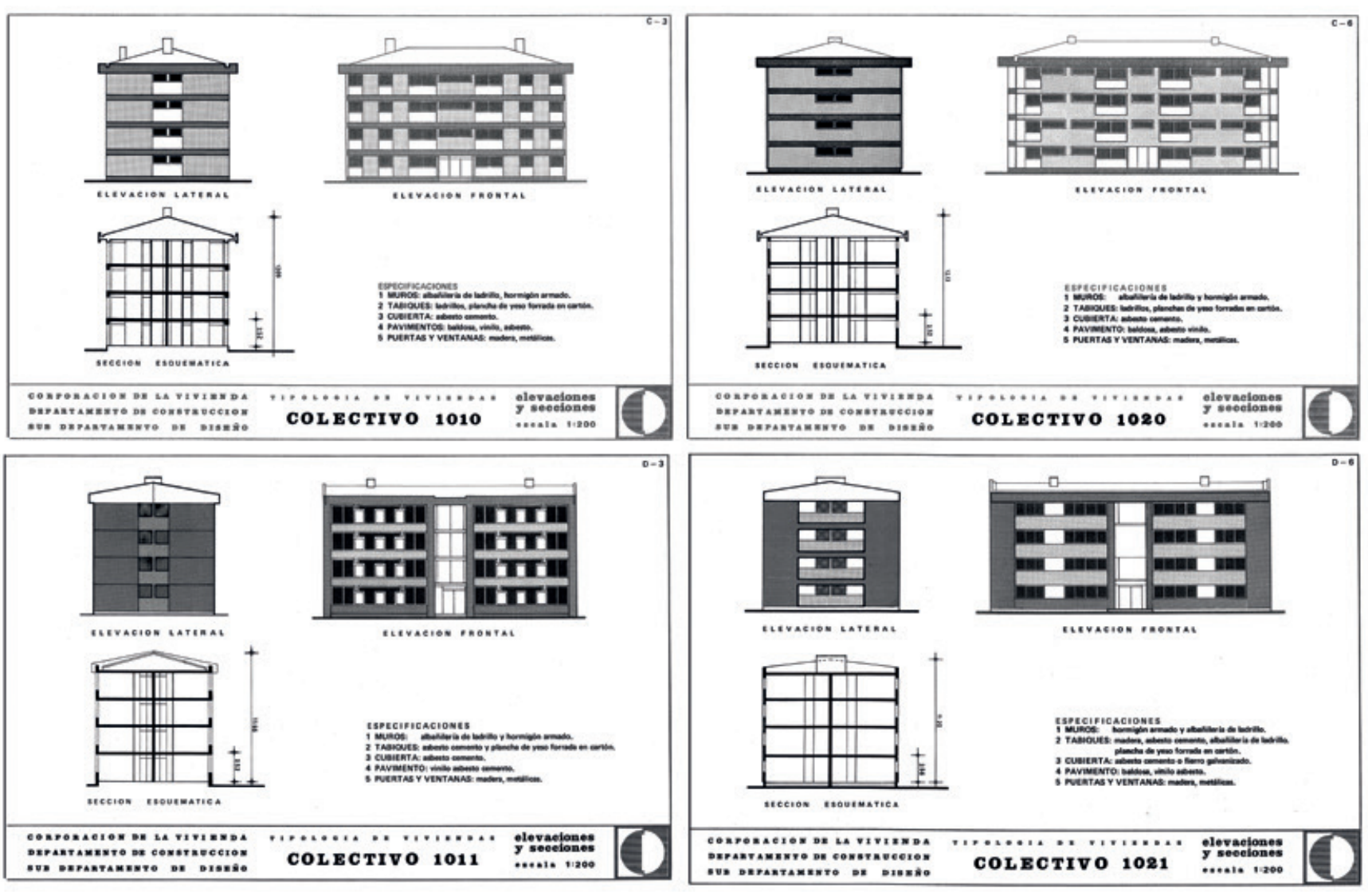

Figura 2

Tipología de

Viviendas Colectivas

en Altura diseñadas

y 1971

Fuente: CORVI

(1972b, p. C1-D14)
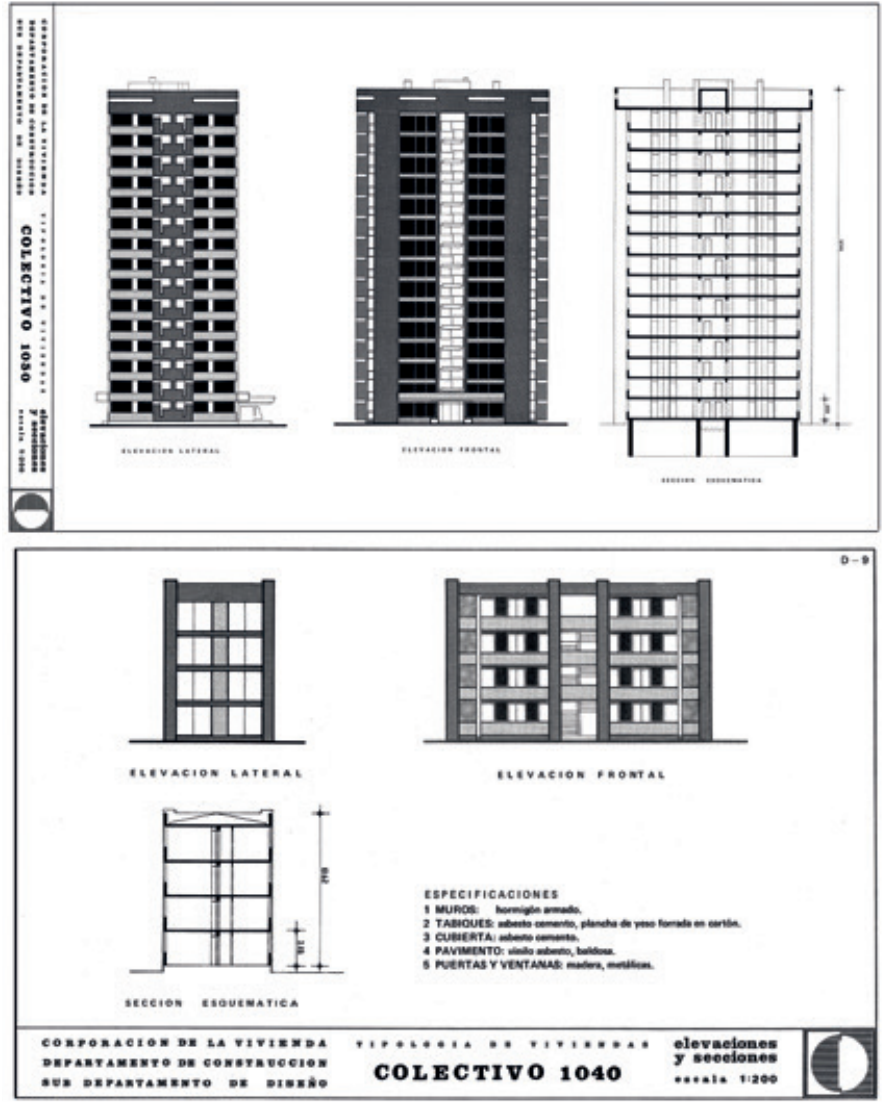
MATERIA

AS / Vol. 39. No59 / ENERO 2021 // ISSN impresa 07 I 6-2677 / ISSN digital 0719-6466

CORVI, TIPOLOGÍAS DE VIVIENDAS RACIONALIZADAS:

UN EJERCICIO DE ESTANDARIZACIÓN
Jorge Eduardo Vergara Vidal, Daniela Álvarez Campos, Denisse Dintrans Bauer y Diego Asenjo Muñoz
En un documento de 1969 titulado "Corporación de la Vivienda" y publicado por la Oficina de Relaciones Públicas de la CORVI, se señala que "los materiales que usa la CORVI en la edificación de vivienda son los siguientes: cemento, arena, ripio, fierro, madera, pizarreño, volcanita, ventanas y marcos metálicos, vidrios sencillos y dobles; baldosas y plástico vinílico; cañerías de cobre; en electricidad: tubos de acera y tubos plásticos; chapas y bisagras corrientes; artefactos sanitarios y pinturas. Todo nacional" (CORVI, 1969, p. I). Contrario a este estilo inespecífico, Tipología de viviendas racionalizadas 1966-1972 establece para cada prototipo la materialidad utilizada en muros, tabiques, cubierta, pavimentos, puertas y ventanas, lo que permite verificar que, si bien hay un cierto número de materialidades que se repiten en el conjunto, también hay elecciones que son específicas para cada prototipo y su localización eventual

\section{[Tabla 2].}

Como es posible notar en la Tabla 2, las variaciones de composición material no son muchas, aunque constructivamente son significativas. Se privilegia la mezcla entre albañilería de ladrillo y hormigón armado en muros de casi todas las tipologías, salvo para las versiones más pequeñas de viviendas y las viviendas de emergencia donde se opta por la madera. En los tabiques se privilegia la plancha de yeso forrada y asbesto cemento, que también se utiliza en las cubiertas y pavimentos, junto a las baldosas. Estas especificaciones consignan alternativas, no composiciones materiales cerradas, por lo mismo no hay precisiones de cantidades a utilizar en cada prototipo. Lo que puede hacer diferencias es el precio y la disponibilidad geográfica, de manera que los prototipos están abiertos materialmente según los presupuestos con que se cuenten. Un ejemplo de lo segundo es que, en cubiertas, se habla indistintamente de "asbesto, cemento", como si fueran dos materialidades diferentes, y de "asbesto cemento", como si fuera una sola, lo cual puede entenderse como parte de la flexibilidad interpretativa necesaria para la adaptación a distintas situaciones de concretización de los prototipos.

Los sistemas constructivos señalados en Tipología de viviendas racionalizadas 1966-1972 son dos: el tradicional, que implica que cada situación es resuelta por las constructoras respectivas; y el semi industrializado, que se aboca a viviendas con paneles fabricados de manera seriada que son ensamblados localmente (Aguirre, Cañas y Vergara, 20 I5). Tal como ocurre con las tecnologías denominadas fluidas (Redfield, 2016), los prototipos de viviendas dan cuenta de dos movimientos epistemológicos diferentes, pero no contradictorios: son parte de un proceso de estandarización que implica un acotamiento de las opciones de forma, función y materialidades de la obra y, al mismo tiempo, está abierto la heterogeneidad de interpretaciones del mundo. Las variaciones requieren de una base; la estandarización desplaza esa base hacia todos los lu- 


\begin{tabular}{|c|c|c|c|c|c|c|c|c|}
\hline \multirow{2}{*}{ Tipo } & \multirow{2}{*}{ Prototipo } & \multirow{2}{*}{$\begin{array}{l}\text { Año de } \\
\text { diseño }\end{array}$} & \multicolumn{5}{|c|}{ Especificaciones } & \multirow{2}{*}{$\begin{array}{l}\text { Presencia } \\
\text { de } \\
\text { Asbestos }\end{array}$} \\
\hline & & & Muros & Tabiques & Cubierta & Pavimento & $\begin{array}{l}\text { Puertas y } \\
\text { Ventanas }\end{array}$ & \\
\hline \multirow{6}{*}{$\begin{array}{l}\text { A. Viviendas } \\
\text { en } \\
\text { Extensión } \\
\text { 1966-1970 }\end{array}$} & N 61 & 1967 & $\begin{array}{l}\text { Albañilería de blo- } \\
\text { que de hormigón }\end{array}$ & $\begin{array}{l}\text { Plancha de yeso forrada } \\
\text { en cartón, asbesto, } \\
\text { cemento }\end{array}$ & Asbesto, cemento & Baldosa & $\begin{array}{l}\text { Madera, } \\
\text { Metálica }\end{array}$ & Sí \\
\hline & 132 & 1966 & $\begin{array}{l}\text { Albañilería ladrillo } \\
\text { reforzada }\end{array}$ & $\begin{array}{l}\text { Plancha de yeso forrada } \\
\text { en cartón }\end{array}$ & Asbesto, cemento & Baldosa & $\begin{array}{l}\text { Madera, } \\
\text { Metálica }\end{array}$ & Sí \\
\hline & 136 & 1966 & $\begin{array}{l}\text { Albañilería ladrillo y } \\
\text { hormigón armado }\end{array}$ & $\begin{array}{l}\text { Plancha de yeso forrada } \\
\text { en cartón, asbesto, } \\
\text { cemento }\end{array}$ & $\begin{array}{l}\text { Asbesto } \\
\text { Cemento, Fierro } \\
\text { Galvanizado }\end{array}$ & $\begin{array}{l}\text { Asbesto vinilo } \\
\text { o palmetas de } \\
\text { vinilo }\end{array}$ & $\begin{array}{l}\text { Madera, } \\
\text { Metálica }\end{array}$ & Sí \\
\hline & sm-196 & 1966 & Madera & Madera & $\begin{array}{l}\text { Fierro } \\
\text { Galvanizado }\end{array}$ & $\begin{array}{l}\text { Madera, vinilo } \\
\text { asbesto }\end{array}$ & Madera & Sí \\
\hline & 197 SM & 1966 & Madera & Madera & $\begin{array}{l}\text { Fierro } \\
\text { Galvanizado }\end{array}$ & $\begin{array}{l}\text { Madera, vinilo } \\
\text { asbesto }\end{array}$ & Madera & Sí \\
\hline & $227 \mathrm{SM}$ & 1966 & Madera & Madera & $\begin{array}{l}\text { Fierro } \\
\text { Galvanizado }\end{array}$ & $\begin{array}{l}\text { Madera, vinilo } \\
\text { asbesto }\end{array}$ & Madera & Sí \\
\hline \multirow{4}{*}{$\begin{array}{l}\text { B. Viviendas } \\
\text { en } \\
\text { Extensión } \\
1971-972\end{array}$} & C-36 & $\begin{array}{l}1970- \\
1971\end{array}$ & $\begin{array}{l}\text { Albañilería ladrillo o } \\
\text { bloque de hormigón } \\
\text { reforzado }\end{array}$ & $\begin{array}{l}\text { Plancha de yeso forrada } \\
\text { en cartón, asbesto, } \\
\text { cemento }\end{array}$ & Asbesto, cemento & Baldosa & $\begin{array}{l}\text { Madera, } \\
\text { Metálica }\end{array}$ & Sí \\
\hline & SM-36 & 1971 & Madera & Madera & $\begin{array}{l}\text { Fierro } \\
\text { Galvanizado }\end{array}$ & $\begin{array}{l}\text { Madera, } \\
\text { Balsoda }\end{array}$ & Madera & No \\
\hline & 150 & 1972 & $\begin{array}{l}\text { Albañilería ladrillo y } \\
\text { hormigón armado }\end{array}$ & $\begin{array}{l}\text { Plancha de yeso forrada } \\
\text { en cartón, madera }\end{array}$ & Pizareño & $\begin{array}{l}\text { Asbesto vinilo, } \\
\text { baldosas }\end{array}$ & $\begin{array}{l}\text { Madera, } \\
\text { Metálica }\end{array}$ & Sí \\
\hline & 250 & 1972 & $\begin{array}{l}\text { Albañilería ladrillo } \\
\text { reforzada }\end{array}$ & $\begin{array}{l}\text { Asbesto, Cemento } \\
\text { Celulosa, Madera }\end{array}$ & $\begin{array}{l}\text { Asbesto } \\
\text { Cemento, Fierro } \\
\text { Galvanizado }\end{array}$ & Baldosa & Metálicas & Sí \\
\hline \multirow{4}{*}{$\begin{array}{l}\text { C. } \\
\text { Colectivos } \\
\text { en Altura - } \\
1966-1970\end{array}$} & 1010 & 1965 & $\begin{array}{l}\text { Albañilería de } \\
\text { ladrillo, hormigón } \\
\text { armado }\end{array}$ & $\begin{array}{l}\text { Plancha de yeso forrada } \\
\text { en cartón, ladrillo }\end{array}$ & Asbesto Cemento & $\begin{array}{l}\text { Baldosa, Vinilo } \\
\text { Asbesto }\end{array}$ & $\begin{array}{l}\text { Madera, } \\
\text { Metálica }\end{array}$ & Sí \\
\hline & & & $\begin{array}{l}\text { Albañilería de } \\
\text { ladrillo, hormigón } \\
\text { armado }\end{array}$ & $\begin{array}{l}\text { Plancha de yeso forrada } \\
\text { en cartón, ladrillo }\end{array}$ & Asbesto Cemento & $\begin{array}{l}\text { Baldosa, Vinilo } \\
\text { Asbesto }\end{array}$ & $\begin{array}{l}\text { Madera, } \\
\text { Metálica }\end{array}$ & Sí \\
\hline & 1020 & 1965 & $\begin{array}{l}\text { Albañilería de } \\
\text { ladrillo, hormigón } \\
\text { armado }\end{array}$ & $\begin{array}{l}\text { Plancha de yeso forrada } \\
\text { en cartón, ladrillo }\end{array}$ & Asbesto Cemento & $\begin{array}{l}\text { Baldosa, Vinilo } \\
\text { Asbesto }\end{array}$ & $\begin{array}{l}\text { Madera, } \\
\text { Metálica }\end{array}$ & Sí \\
\hline & & & $\begin{array}{l}\text { Albañilería de } \\
\text { ladrillo, hormigón } \\
\text { armado }\end{array}$ & $\begin{array}{l}\text { Plancha de yeso forrada } \\
\text { en cartón, ladrillo }\end{array}$ & Asbesto Cemento & $\begin{array}{l}\text { Baldosa, Vinilo } \\
\text { Asbesto }\end{array}$ & $\begin{array}{l}\text { Madera, } \\
\text { Metálica }\end{array}$ & Sí \\
\hline \multirow{6}{*}{$\begin{array}{l}\text { D. } \\
\text { Colectivos } \\
\text { en Altura - } \\
\text { 1971-1972 }\end{array}$} & 1011 & 1972 & $\begin{array}{l}\text { Albañilería de } \\
\text { ladrillo, hormigón } \\
\text { armado }\end{array}$ & $\begin{array}{l}\text { Plancha de yeso forrada } \\
\text { en cartón, ladrillo }\end{array}$ & Asbesto Cemento & $\begin{array}{l}\text { Vinilo asbesto } \\
\text { cemento }\end{array}$ & $\begin{array}{l}\text { Madera, } \\
\text { Metálica }\end{array}$ & Sí \\
\hline & & & $\begin{array}{l}\text { Albañilería de } \\
\text { ladrillo, hormigón } \\
\text { armado }\end{array}$ & $\begin{array}{l}\text { Plancha de yeso forrada } \\
\text { en cartón, ladrillo }\end{array}$ & Asbesto Cemento & $\begin{array}{l}\text { Vinilo asbesto } \\
\text { cemento }\end{array}$ & $\begin{array}{l}\text { Madera, } \\
\text { Metálica }\end{array}$ & Sí \\
\hline & 1021 & 1971 & $\begin{array}{l}\text { Albañilería de } \\
\text { ladrillo, hormigón } \\
\text { armado }\end{array}$ & $\begin{array}{l}\text { Plancha de yeso forrada } \\
\text { en cartón, albañilería de } \\
\text { ladrillo, madera, asbesto } \\
\text { cemento }\end{array}$ & $\begin{array}{l}\text { Asbesto } \\
\text { Cemento o fierro } \\
\text { galvanizado }\end{array}$ & $\begin{array}{l}\text { Baldosa, Vinilo } \\
\text { Asbesto }\end{array}$ & $\begin{array}{l}\text { Madera, } \\
\text { Metálica }\end{array}$ & Sí \\
\hline & & & $\begin{array}{l}\text { Albañilería de } \\
\text { ladrillo, hormigón } \\
\text { armado }\end{array}$ & $\begin{array}{l}\text { Plancha de yeso forrada } \\
\text { en cartón, albañilería de } \\
\text { ladrillo, madera, asbesto } \\
\text { cemento }\end{array}$ & $\begin{array}{l}\text { Asbesto } \\
\text { Cemento o fierro } \\
\text { galvanizado }\end{array}$ & $\begin{array}{l}\text { Baldosa, Vinilo } \\
\text { Asbesto }\end{array}$ & $\begin{array}{l}\text { Madera, } \\
\text { Metálica }\end{array}$ & Sí \\
\hline & 1040 & 1972 & Hormigón Armado & $\begin{array}{l}\text { Plancha de yeso forrada } \\
\text { en Asbesto Cemento }\end{array}$ & Asbesto Cemento & $\begin{array}{l}\text { Baldosa, Vinilo } \\
\text { Asbesto }\end{array}$ & $\begin{array}{l}\text { Madera, } \\
\text { Metálica }\end{array}$ & Sí \\
\hline & 1050 & 1972 & Hormigón Armado & $\begin{array}{l}\text { Plancha de yeso forrada } \\
\text { en cartón, Asbesto } \\
\text { Cemento }\end{array}$ & Terraza Baldosa & $\begin{array}{l}\text { Baldosa, Vinilo } \\
\text { Asbesto }\end{array}$ & $\begin{array}{l}\text { Madera, } \\
\text { alumno }\end{array}$ & Sí \\
\hline \multirow{2}{*}{$\begin{array}{l}\text { E. Viviendas } \\
\text { de } \\
\text { Emergencia }\end{array}$} & e19 & - & Madera & S/información & Madera & S/información & Madera & Sí \\
\hline & e21 & - & Madera & S/información & Madera & S/información & Madera & Sí \\
\hline
\end{tabular}


Tabla 2

Especificaciones materiales de prototipos de viviendas racionalizadas CORVI 1965-1972.

Fuente: Elaboración de autores a partir de CORVI (1972b).

\section{DIMENSIONES}

gares, como parte de un proceso evolutivo de las mismas. Mientras la adopción del estándar tipológico gubernamentaliza el diseño y la construcción de viviendas, también ayuda a sus desplazamientos, a sus adaptaciones. La estandarización no cierra el diseño, el estándar abre la tecnología a la adaptación local.

En lo que refiere a las dimensiones de las viviendas, es posible encontrar que cada prototipo presenta dimensiones diferentes, pero dentro de un marco que limita su varianza. La altura de las habitaciones tiene un promedio de 2,3 metros, pero siete prototipos tienen una altura de 2,52 metros y otros cinco, de 2,20 metros, lo que fija una moda. Algo similar ocurre con el ancho de muros, cuando se entrega información sobre este aspecto, éste tiene valores de entre 15 a 20 centímetros, aunque, cabe mencionar, que el ancho de los tabiques venía dimensionado de fábrica de manera estándar [Figuras 3 y 4].

El conjunto de las variaciones de dimensiones que se puede apreciar en la Tabla 3 evidencia un amplio abanico de opciones que fueron consideradas para elaborar los prototipos y que tiene como resultado una estandarización flexible. Así como esto es el producto del trabajo de varios equipos de diseño, no hay una fórmula que impere sobre otra. Los acuerdos de dimensiones tomados dentro del
Figura 3

Dimensiones y plantas de viviendas en extensión diseñadas en CORVI entre 1966 y 1971 .

Fuente: CORVI (1972b, p. $\mathrm{A} 1-\mathrm{E} 2)$.

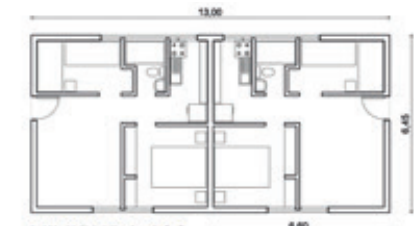

\section{VIVIENDA 132}
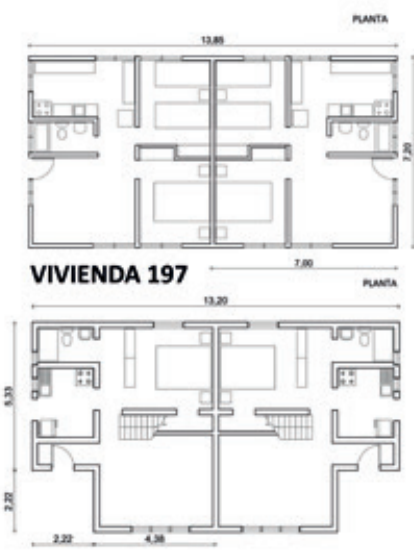

VIVIENDA 227

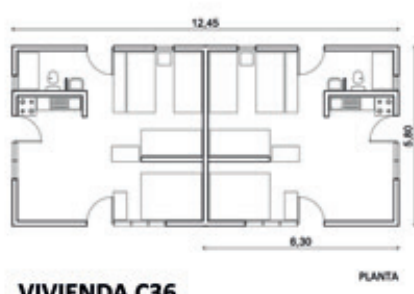

VIVIENDA C36
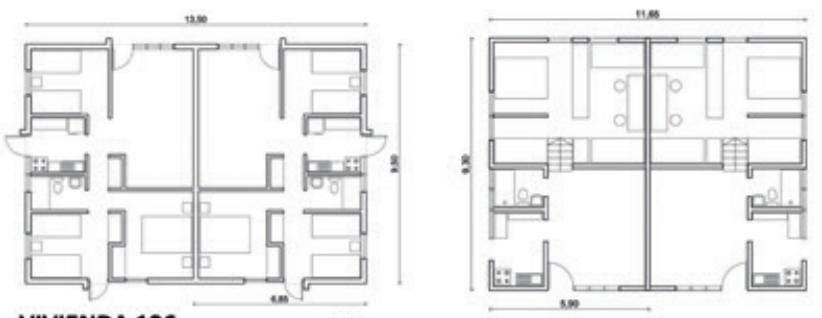

VIVIENDA 136

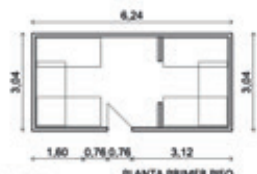

VIVIENDA E19

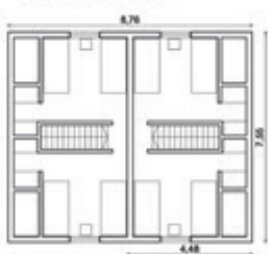

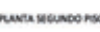

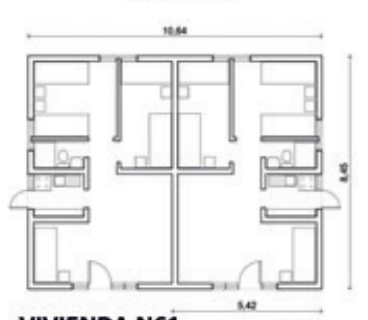

VIVIENDA N61

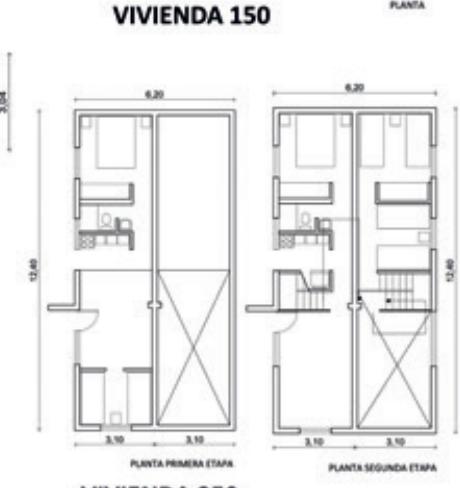

VIVIENDA 250

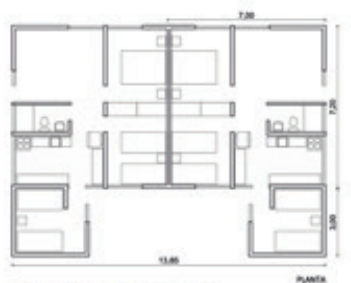

VIVIENDA SM196 
Figura 4

Dimensiones y

plantas de viviendas

colectivas en altura

diseñadas en CORVI

entre 1966 y 1971

Fuente: CORVI (1972b, p. C1-D14)
Departamento de Estudio que diseña los prototipos de colectivos 1010 y 1020 [Figura 2], no se replican en las decisiones tomadas en Departamento Sur respecto de las dimensiones de las viviendas en extensión, tanto porque van hacia públicos diferentes como porque se proyectan para situaciones diferentes, como ocurre con la vivienda I50, diseñada para un terreno con dos niveles, o la vivienda e-2 I, diseñada para emergencias [Figura I].

Ahora bien, hay casos, como los prototipos de viviendas 196 y 197 , diseñados por el mismo equipo en el mismo año, pero regionalizados para distintas zonas (norte y sur) son exactamente iguales en su diseño y materialidad, no hay diferencia entre ellas. Los prototipos de viviendas C36 y SM 36, diseñados por el mismo equipo, con diferencia de un año, para distintas zonas (central y todo el país), son diferentes en dimensiones y materialidades, no obstante, su distribución programática es igual en el dibujo. Incluso la SM36 no contabiliza un pequeño pasillo que aparece en el dibujo y al que otorga metros en las especificaciones de la C36. El resultado son dibujos similares, pero metrajes diferentes: 34 metros cuadrados (C36) y 35,44 metros cuadrados (SM 36) de superficie útil cada una. Por su parte, el prototipo I 50 correspondía a una vivienda de una planta, pero en dos niveles, adaptable específicamente a laderas con una pendiente elevada [Figura I].
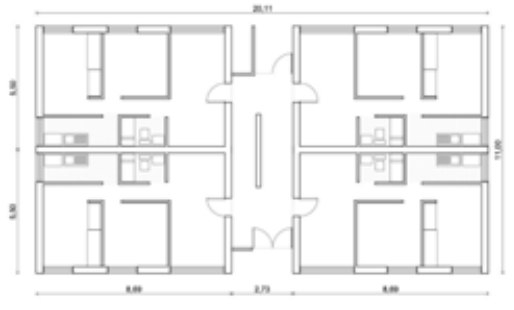

COLECTIVO 1010
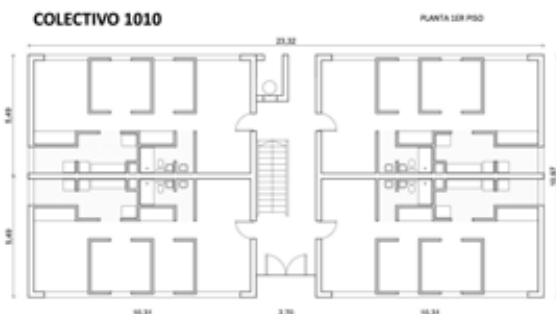

\section{COLECTIVO 1011}

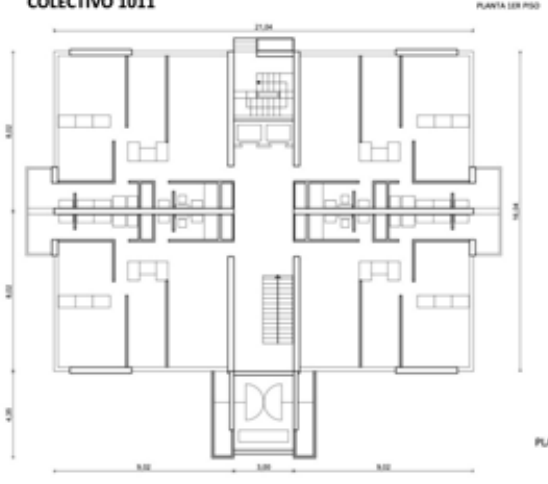

manson

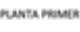

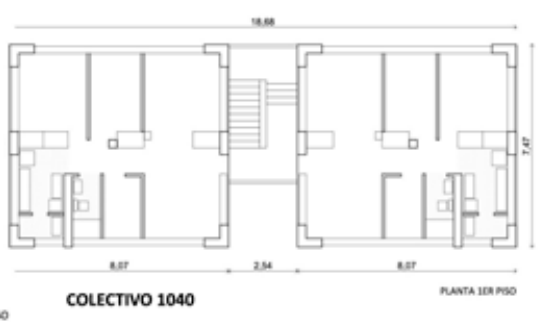

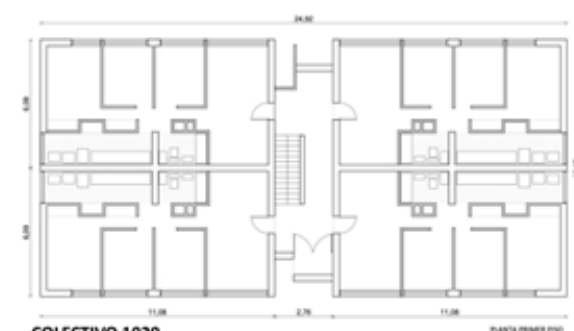

COLECTIVO 1020

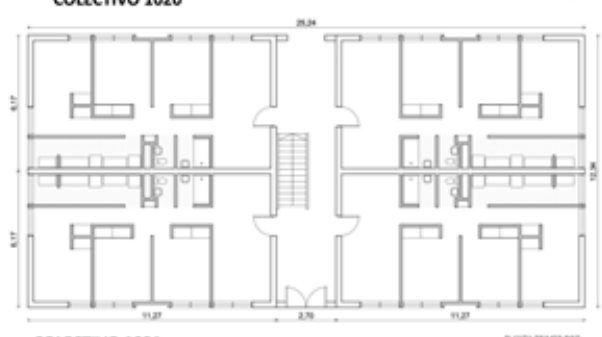

COLECTIVO 1021

COLECTIVO 1040

COLectivo 1050 
Tabla 3

Dimensiones (en metros cuadrados)

de prototipos de viviendas

racionalizadas, CORVI 1965-1972.

Fuente: Elaboración de autores a

partir de CORVI (1972b).

\begin{tabular}{|c|c|c|c|c|c|c|c|c|c|}
\hline Tipo & Prototipo & Año & $\begin{array}{l}\text { Tipología } \\
\text { de vivienda }\end{array}$ & $\begin{array}{l}\text { Modelo } \\
\text { vivienda }\end{array}$ & Altura & $\begin{array}{c}\text { Ancho } \\
\text { de muros } \\
\text { estructurales }\end{array}$ & $\begin{array}{l}\text { Largo } \\
\text { frontal } \\
\text { (incluido } \\
\text { muro) }\end{array}$ & $\begin{array}{l}\text { Largo } \\
\text { lateral } \\
\text { (incluido } \\
\text { muro) }\end{array}$ & $\begin{array}{c}\text { Total } \\
\text { m2 de } \\
\text { vivienda }\end{array}$ \\
\hline \multirow{6}{*}{$\begin{array}{l}\text { A. Viviendas en } \\
\text { Extensión 1966- } \\
1970\end{array}$} & N 61 & 1967 & Pareada & $A$ & 2,2 & 0,2 & 5,42 & 8,45 & 38,89 \\
\hline & 132 & 1966 & Pareada & $A$ & 2,2 & 0,2 & 6,6 & 6,45 & 36,93 \\
\hline & 136 & 1966 & Pareada & $A$ & 2,2 & $n / i$ & 6,85 & 9,5 & 57,81 \\
\hline & sm-196 & 1967 & Pareada & $A$ & 2,35 & 0,15 & 10,2 & 7 & 52,26 \\
\hline & 197 SM & 1967 & Pareada & $A$ & 2,41 & 0,15 & 7,2 & 7 & 52,26 \\
\hline & $227 \mathrm{SM}$ & 1967 & Pareada & $A$ & 2,2 & $n / i$ & 6,75 & 7,55 & 62,34 \\
\hline \multirow{4}{*}{$\begin{array}{l}\text { B. Viviendas en } \\
\text { Extensión 1971- } \\
972\end{array}$} & C-36 & 1970-1971 & Pareada & $A$ & 2,18 & 0,15 & $6,30 / 6,40$ & 5,8 & 34 \\
\hline & SM-36 & 1971 & Pareada & $A$ & 2,4 & 0,15 & 6,4 & 5,8 & 35,44 \\
\hline & 150 & 1972 & Pareada & $A$ & 2,2 & 0,15 & 6,2 & 9,3 & 49,32 \\
\hline & 250 & 1972 & Pareada & $A$ & 2 & $n / i$ & 12,4 & 6,2 & 33,36 \\
\hline \multirow{4}{*}{$\begin{array}{l}\text { C. Colectivos en } \\
\text { Altura - 1966- } \\
1970\end{array}$} & \multirow{2}{*}{1010} & \multirow{2}{*}{1965} & \multirow{2}{*}{ Aislada } & $A$ & 2,52 & $\mathrm{n} / \mathrm{i}$ & 5,54 & 8,69 & 44,06 \\
\hline & & & & B & 2,52 & $n / i$ & 5,54 & 11,52 & 50 \\
\hline & \multirow{2}{*}{1020} & \multirow{2}{*}{1965} & \multirow{2}{*}{ Aislada } & $A$ & 2,52 & $n / i$ & 6,085 & 11,08 & 58,99 \\
\hline & & & & B & 2,52 & $n / i$ & 6,085 & 14,01 & 66,95 \\
\hline \multirow{6}{*}{$\begin{array}{l}\text { D. Colectivos en } \\
\text { Altura - 1971- } \\
1972\end{array}$} & \multirow{2}{*}{1011} & \multirow{2}{*}{1972} & \multirow{2}{*}{ Aislada } & $A$ & 2,52 & $n / i$ & 6,085 & 11,08 & 58,99 \\
\hline & & & & $B$ & 2,52 & $n / i$ & 6,085 & 14,01 & 66,95 \\
\hline & \multirow{2}{*}{1021} & \multirow{2}{*}{1971} & \multirow{2}{*}{ Aislada } & $A$ & 2,52 & $n / i$ & 5,485 & 10,31 & 48,87 \\
\hline & & & & $B$ & 2,52 & $n / i$ & 5,485 & 11,66 & 52,98 \\
\hline & 1040 & 1972 & $\begin{array}{l}\text { Aislada / } \\
\text { Pareada }\end{array}$ & $A$ & 2,56 & $n / i$ & 6,17 & 11,27 & 60,55 \\
\hline & 1050 & 1972 & $\begin{array}{l}\text { Aislada / } \\
\text { Pareada }\end{array}$ & $B$ & 2,56 & $n / i$ & 6,17 & 14,045 & 67,65 \\
\hline \multirow{2}{*}{$\begin{array}{l}\text { E. Viviendas de } \\
\text { Emergencia }\end{array}$} & $\begin{array}{c}\text { e19 } \\
\text { (emergencia) }\end{array}$ & $\begin{array}{l}\text { S/informa- } \\
\text { ción }\end{array}$ & Aislada & A & 2,8 & $n / i$ & 2,5 & 6 & 21 \\
\hline & e21 & $\begin{array}{l}\text { S/informa- } \\
\text { ción }\end{array}$ & Aislada & $A$ & 2,15 & $n / i$ & 6,24 & 3,04 & 18,96 \\
\hline
\end{tabular}




\section{PROGRAMAS}

\section{CONCLUSIONES}

AS / Vol. 39. No59 / ENERO 2021 // ISSN impresa 07 I 6-2677 / ISSN digital 0719-6466

CORVI, TIPOLOGÍAS DE VIVIENDAS RACIONALIZADAS:

UN EJERCICIO DE ESTANDARIZACIÓN

Jorge Eduardo Vergara Vidal, Daniela Álvarez Campos, Denisse Dintrans Bauer y Diego Asenjo Muñoz
Un aspecto que motiva mayores similitudes estructurales entre los diferentes prototipos es el de los programas, que igualmente tiene relación con la estandarización de las dimensiones internas. Todos los prototipos presentan programas similares: estar/comedor, cocina, baño, dormitorio, pasillo y clóset, lo que constituye uno de los resultados de la estandarización del diseño de las viviendas realizado por CORVI. Si bien las dimensiones dedicadas a cada actividad varían dentro de cada prototipo, en promedio, la superficie dedicada en ellos al Estar y Comer corresponde al 27\%, al Cocinar un $11 \%$, al Higiene un 6\%, al Dormir un $45 \%$ (un $21 \%$ al dormitorio principal y un $24 \%$ de superficie al resto), un 6\% de espacio dedicado a las circulaciones y un $4 \%$ dedicado al guardar [Tabla 4]. Cabe señalar que la división programática propuesta no solo indica una racionalización de las actividades y de sus infraestructuras sino también una concepción familiar de los habitantes y una jerarquización dentro de ello, en la medida que se establece un dormitorio principal y se le asigna un espacio más holgado.

Las casas presentan, por cada prototipo, unidades de vivienda de dimensiones homogéneas. Los colectivos, en cambio, contienen unidades de vivienda con distintas dimensiones y tipos. Los colectivos I 010 y 1020, por ejemplo, tienen cuatro plantas: la primera contiene cuatro unidades de vivienda de tipo A, mientras las siguientes incluyen tres de tipo A y una de tipo B. Esta última incluye un dormitorio más o un espacio que se contabiliza en los metros de superficie útil como tal, aunque en el dibujo aparece como extensión del estar/comedor. En los colectivos 1010 hay viviendas de 2 (A) y 3 (B) dormitorios, donde $A$ es el dormitorio principal y los $B$ son de menor pero igual dimensión. En los colectivos 1020 hay viviendas de 3 (A) y 4 (B) dormitorios; aquí se consideran dos unidades de mayor tamaño y dos de menor tamaño, ambos pares iguales.

La revisión expuesta permite fijar cuatro variables involucradas en el diseño de viviendas en que se puede notar un intento de estandarización en el trabajo CORVI. Su particularidad radica en que no busca un modelo rígido, sino uno flexible. Las medidas no son iguales entre prototipos, ni se expresan cubicaciones acotadas; por el contrario, entregan una idea posible de ser interpretada dentro de un marco establecido, de manera que tanto quien decide qué tipología de vivienda construir, como quien quiere imaginar su funcionamiento, tienen la posibilidad de especular sobre ellas y tomar decisiones respecto de su concretización. Sin embargo, no pueden hacer lo mismo sobre los aspectos estructurales de las viviendas, ya que sus formas, programas, materialidades y espacios ya se encuentran delimitados y son coincidentes entre ellos.

Dicho de otra manera, el diseño de las tipologías de vivienda CORVI está estandarizado por la idea de racionalización de modo que, independiente de las variaciones entre sí, el conjunto de los prototipos actúa socio-materialmente de manera similar. Sus elecciones materiales permiten suponer una durabilidad que, vistos los casos en la actua- 
Tabla 4

Dimensiones (en metros cuadrados) de recintos habitables en prototipos de viviendas racionalizadas, CORVI 19651972 .

Fuente: Elaboración de autores a

partir de CORVI (1972b).

\begin{tabular}{|c|c|c|c|c|c|c|c|c|c|c|c|c|}
\hline Tipo & Prototipo & Año & $\begin{array}{c}\text { Tipología } \\
\text { de } \\
\text { vivienda }\end{array}$ & $\begin{array}{l}\text { Modelo } \\
\text { vivienda }\end{array}$ & $\begin{array}{c}\text { Estar } \\
\text { Comedor }\end{array}$ & Cocina & Baño & $\begin{array}{c}\text { Dormitorio } \\
1 \text { (y } 4 \text { si lo } \\
\text { hay) }\end{array}$ & $\begin{array}{c}\text { Dormitorio } \\
2 \text { y } 3\end{array}$ & Pasillo & Clóset & $\begin{array}{c}\text { Total } \\
\mathrm{m} 2 \mathrm{de} \\
\text { vivienda }\end{array}$ \\
\hline \multirow{6}{*}{$\begin{array}{l}\text { A. Viviendas } \\
\text { en Extensión } \\
1966-1970\end{array}$} & N 61 & 1967 & Pareada & A & 11,37 & 3,18 & 2,08 & 8,56 & 12,66 & 1,04 & 0 & 38,89 \\
\hline & 132 & 1966 & Pareada & A & 12,04 & 4,68 & 2,57 & 8,81 & 6,48 & 1,14 & 1,21 & 36,93 \\
\hline & 136 & 1966 & Pareada & A & 17,96 & 4,79 & 3,29 & 10,16 & 16,45 & 3,16 & 2 & 57,81 \\
\hline & sm-196 & 1967 & Pareada & A & 13,23 & 8,17 & 2,89 & 8,63 & 16,12 & 1,6 & 1,62 & 52,26 \\
\hline & 197 SM & 1967 & Pareada & A & 13,23 & 8,17 & 2,89 & 8,63 & 16,12 & 1,6 & 1,62 & 52,26 \\
\hline & $227 \mathrm{SM}$ & 1967 & Pareada & A & 13,3 & 5 & 3,22 & 12,32 & 19,67 & 4,08 & 4,75 & 62,34 \\
\hline \multirow{4}{*}{$\begin{array}{l}\text { B. Viviendas } \\
\text { en Extensión } \\
1971-972\end{array}$} & $C-36$ & $\begin{array}{l}1970- \\
1971\end{array}$ & Pareada & A & 7,8 & 3,3 & 2,64 & 8,01 & 8,01 & 2,24 & 2 & 34 \\
\hline & SM-36 & 1971 & Pareada & A & 8,23 & 4,94 & 3,29 & 8,49 & 8,49 & 0 & 2 & 35,44 \\
\hline & 150 & 1972 & Pareada & A & 15,12 & 5,3 & 4,9 & 7,95 & 13,12 & 0,77 & 2,16 & 49,32 \\
\hline & 250 & 1972 & Pareada & A & 11,2 & 2,6 & 2,4 & 8,68 & 5,88 & 1,6 & 1 & 33,36 \\
\hline \multirow{4}{*}{$\begin{array}{l}\text { C. } \\
\text { Colectivos } \\
\text { en Altura - } \\
\text { 1966-1970 }\end{array}$} & \multirow{2}{*}{1010} & \multirow{2}{*}{1965} & \multirow{2}{*}{ Aislada } & A & 13,63 & 4,78 & 2,4 & 11,26 & 8,28 & 2,26 & 1,45 & 44,06 \\
\hline & & & & B & 13,63 & 4,78 & 2,4 & 11,26 & 14,22 & 2,26 & 1,45 & 50 \\
\hline & \multirow{2}{*}{1020} & \multirow{2}{*}{1965} & \multirow{2}{*}{ Aislada } & A & 16,2 & 8,15 & 3,31 & 9,52 & 14,22 & 5,62 & 1,97 & 58,99 \\
\hline & & & & B & 16,2 & 8,15 & 3,31 & 17,48 & 14,22 & 5,62 & 1,97 & 66,95 \\
\hline \multirow{6}{*}{$\begin{array}{l}\text { D. } \\
\text { Colectivos } \\
\text { en Altura - } \\
\text { 1971-1972 }\end{array}$} & \multirow{2}{*}{1011} & \multirow{2}{*}{1972} & \multirow{2}{*}{ Aislada } & A & 13,77 & 6,47 & 3,43 & 8,91 & 10,15 & 3,98 & 2,16 & 48,87 \\
\hline & & & & B & 13,77 & 6,47 & 3,43 & 13,02 & 10,15 & 3,98 & 2,16 & 52,98 \\
\hline & \multirow{2}{*}{1021} & \multirow{2}{*}{1971} & \multirow{2}{*}{ Aislada } & A & 15,48 & 7,03 & 3,74 & 10,31 & 15,3 & 5,45 & 3,24 & 60,55 \\
\hline & & & & B & 15,48 & 7,03 & 3,74 & 17,41 & 15,3 & 5,45 & 3,24 & 67,65 \\
\hline & 1040 & 1972 & $\begin{array}{l}\text { Aislada / } \\
\text { Pareada }\end{array}$ & A & 17,71 & 5,87 & 2,42 & 8,24 & 10,26 & 2,94 & 2,16 & 49,6 \\
\hline & 1050 & 1972 & $\begin{array}{l}\text { Aislada / } \\
\text { Pareada }\end{array}$ & B & 16,28 & 7,69 & 4,52 & 9,88 & 15,77 & 4,75 & 3,63 & 62,52 \\
\hline \multirow{2}{*}{$\begin{array}{l}\text { E. Viviendas } \\
\text { de } \\
\text { Emergencia }\end{array}$} & $\begin{array}{c}\text { e19 } \\
\text { (emergencia) }\end{array}$ & $\begin{array}{l}\text { S/infor- } \\
\text { mación }\end{array}$ & Aislada & A & 7 & 0 & 0 & 7 & 7 & 0 & 0 & 21 \\
\hline & e21 & $\begin{array}{l}\text { S/infor- } \\
\text { mación }\end{array}$ & Aislada & A & 6,32 & 0 & 0 & 6,32 & 6,32 & 0 & 0 & 18,96 \\
\hline
\end{tabular}


Figura 5

Dimensiones y

plantas de viviendas

colectivas en altura

diseñadas en CORVI

entre 1966 y 1971.

de autores

Figura 6

Dimensiones y

plantas de viviendas

colectivas en altura

diseñadas en CORVI

entre 1966 y 1971.

Fuente: Elaboración

de autores lidad, se extienden por sobre los cincuenta años. Sus formas, dimensiones y distribuciones programáticas hacen posible prever la habitación de familias nucleares, que evolucionan, y que son sustentables en el tiempo si los núcleos familiares decrecen. Ambos parámetros sugieren una vivienda funcional al ciclo de vida de las familias que las adquieren, que estabilizan su entorno urbano y que provienen de un aprendizaje de las experiencias anteriores y contemporáneas.

En esto, como ya se mencionó, la noción de tipología puede llamar a error. Rafael Moneo (1978; 2015$)$ sostiene que los momentos más intensos en la historia de la arquitectura son aquellos donde una nueva tipología emerge, fenómeno en el cual colaboran elementos externos, como la disponibilidad de nuevas técnicas o la urgencia de nuevos requerimientos sociales. Para Moneo, un momento tipológico es un hito particular, que marca la producción de las obras de arquitectura en el mediano plazo y tiene un efecto en las formas socio-materiales de entendimiento y/o reflexión de esta comunidad de prácticas. Por cierto, las tipologías de edificaciones diseñadas por los equipos CORVI no promueven formas arquitectónicas nuevas o distintas de las formas modernas prexistentes, sino más bien articulan versiones sincréticas de éstas, y en ello está su virtud [Figura 5]. Evidencian un momento de la comunidad de prácticas de la arquitectura chilena en que ésta cuenta con un buen número de referentes de
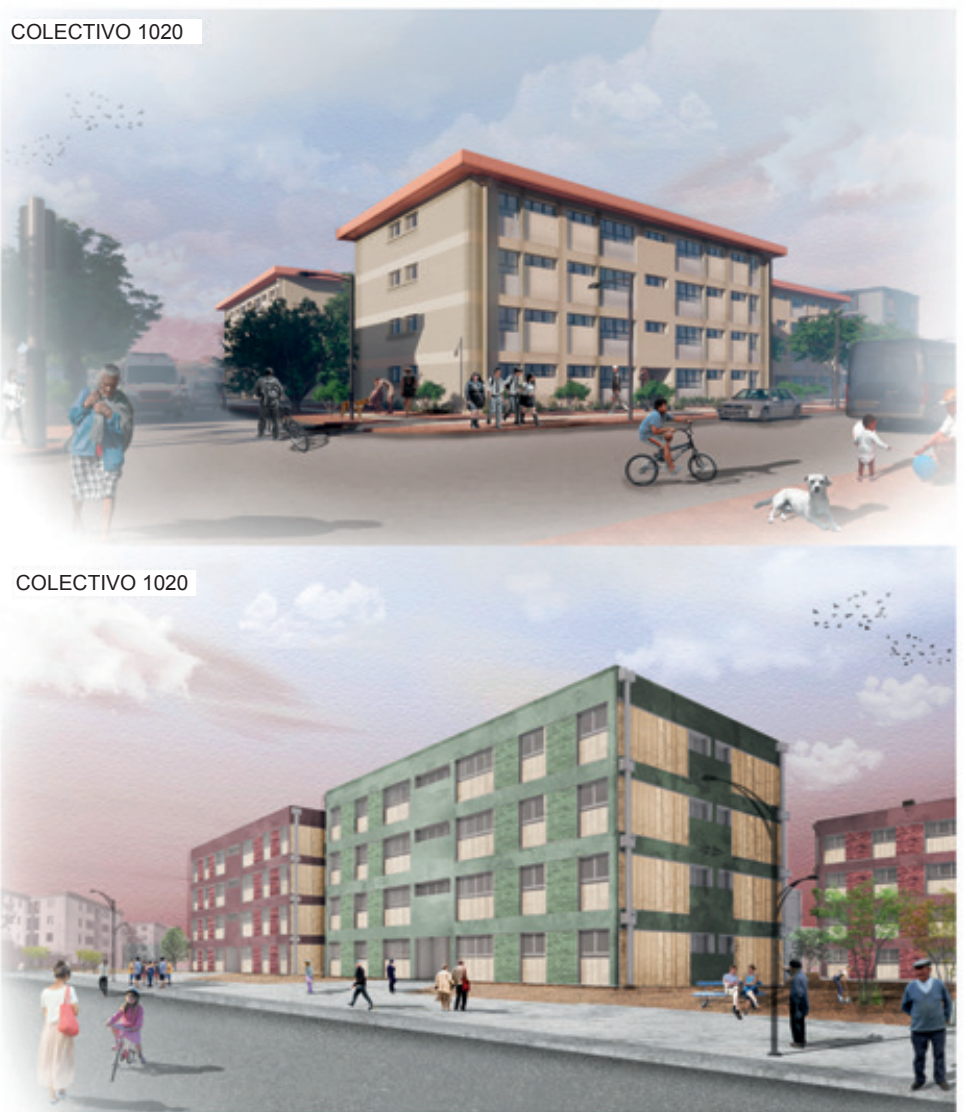
viviendas de interés social, producidos en las casi siete décadas precedentes, y además un mandato claro, referido a simplificar los procesos de composición material y de producción de estas.

Se trabaja, además, dentro de una narrativa social que ha sido persistente: la modernización, en cuyo progreso las distintas vertientes de la arquitectura y de la política confían, y en cuyo marco los esfuerzos por estandarizar o racionalizar los procesos productivos, así como los intentos por industrializarlos, son vistos generalmente como avances positivos (Quintela, 1972). Tipologías de viviendas racionalizadas 19661972 da cuenta de las particularidades de ese momento. Su intensidad puede apreciarse tanto en el número de versiones diferentes de habitar que producen los equipos de diseño CORVI (I8) como en la intensión adaptativa de su lenguaje de programas, materialidades y formas básicas a tales versiones. Al mismo tiempo, este ejercicio de diseño consolida tres tipos de estrategias tipológicas para la vivienda de interés social: casas pareadas, bloques aislados y edificios residenciales en altura. En las décadas posteriores veremos como el debate se centra entre casas, que expanden las periferias de las ciudades, y edificios en altura, que densifican sus centros (Vergara, 2017), pero en este momento los principales protagonistas resultaron ser las bloques aislados o colectivos, formas intermedias de densificación que coincidían con las densidades de manzanas planificadas.

Los colectivos, en especial los modelos 1010 y 1020 [Figura 6], resultaron exitosos tanto por el número en que fueron producidos, sino sobre todo ser extendidos gran parte de las ciudades del país, aunque solo estaban diseñados para la zona central. Su flexibilidad interpretativa como tipología les permitió ser adaptados para zonas climáticas opuestas (Arica y Punta Arenas, por ejemplo) sin sufrir variaciones en sus programas, de manera que independiente de que la pendiente de sus techos de dos aguas, o de sus recubrimientos, sus habitantes compartían la experiencia residencial esperada por sus diseñadores: living-comedor, roperos, pasillos, dormitorios diferenciados, cocina con loggia, dentro de departamentos de 60 metros cuadrados insertos en unidades colectivas. Estas propuestas de habitar perderán rigor una vez que CORVI deje de producirlas, hacia fines de la década de 1970, pero su influencia es notable en las viviendas de interés social posteriores, que buscarán mantener las formas, las materialidades y los programas a pesar de reducir su calidad y dimensiones, debido a que las formas de residencialidad que estos programas presentaban ya se habían consolidado en la sociedad chilena.

Establecer las obras precedentes que fueron analizadas por los equipos de diseño CORVI resulta algo difícil. Se sabe que eran referentes de la Ley de Habitaciones Obreras, de la Ley Pereira y del DFL 2, de manera que las poblaciones Huemul I, II, y III fueron consideradas, así como otras ubicadas en Antofagasta y Valparaíso. Cabe considerar también que entre quienes participaron en los talleres de análisis no solo estaba Valdés, quien venía de inaugurar las Torres de Tajamar 
y Villa Portales, sino también Sepúlveda y Perelman que venían de concluir Remodelación República. Con todo, lo central es rescatar que, en estos ejercicios de diseño, CORVI contó con las "síntesis de las mejores aportaciones individuales para solucionar determinados problemas repetitivos" (Benévolo, 1963, p. 883), en este caso, de la vivienda de interés social en función de "corregir la anarquía de tipos de vivienda" (Quiroga, 1972, p. 42) que percibía la política pública.

A pesar de que los equipos de CORVI no elaboran un forma arquitectónica nueva, tanto el encargo de diseño que reciben como las tres tipologías generales que proponen en sus dieciocho prototipos, traen ideas dentro suyo que se consolidan a través de ellas en la sociedad: la de familia nuclear con jerarquías internas; la del habitar urbano como habitar colectivo; el uso de las materialidades sólidas para la vivienda (ladrillo y hormigón) que se asocia a la de una vivienda que acompaña el ciclo vital y que constituye un bien duradero; la separación física entre los programas de estar, dormir y preparar alimentos; entre otras son solo algunas de ellas, por lo que es posible sostener que se está frente a un momento especial para el diseño dentro de la arquitectura chilena, cuyo efectos deben ser dimensionados en función de la estandarización de la vivienda de interés social, la consolidación de tipologías de habitar colectivo y de un momento material en las ciudades chilenas, más allá de la valoración sobre la singularidades de las obras, y si bien este momento no deviene en la fijación de un estándar definitivo de vivienda, es parte de la experimentación que ayuda a organizar diseños "para un uso repetitivo, serializado, a escala nacional" (Quiroga, 1972, p. 42).

Cabe considerar que la estandarización de las formas, materiales, dimensiones y programas realizados por los equipos CORVI, y contenidas en "Tipologías de viviendas racionalizadas 1966-1972", no conlleva fórmulas o indicaciones rígidas, sino más bien en orientaciones de diseño interpretativamente flexibles $y$ adecuables situadamente, lo que coincide con la función sociológica de los estándares revisada al principio de este trabajo. Pero además existe, en las dieciocho tipologías propuestas, una comunalidad estructural que expresa un modo de producir vivienda, en la que el diseño proyectual es la pieza central de un argumento colectivo para el habitar, no solo a escala del conjunto residencial, sino también a escala de los segmentos económicos que accedín a dichas viviendas y que producía una cohesión simbólica en la escala nacional.

De la reflexión que emana de los diseños de los equipos CORVI es posible aprender tanto las bondades del diseño tipológico, basado en la racionalización de gasto y en la estandarización de materialidades y programas involucrados en la producción de viviendas de interés social, como las virtudes de la flexibilidad de la estandarización, que permite su adecuación a las distintas realidades urbanas del país. Esta reflexión debiera ser tomada en cuenta para la optimización de los estándares de vivienda de interés social y para abordar seriamente el habitar colectivo como una política pública futura. 


\section{REFERENCIAS BIBLIOGRÁFICAS}

AGUIRRE, B., CAÑAS, N., VERGARA, F. (2015). Sobre la arquitectura prefabricada en Chile 1960-1973. Revista de Diseño Urbano y Paisaje, (29), 34-51.

BENÉVOLO, L. (1963). Historia de la Arquitectura Moderna. Madrid: Taurus.

Corporación de la Vivienda (CORVI) (1969). La Corporación de la Vivienda. Santiago de Chile: Oficina de Relaciones Públicas CORVI.

Corporación de la Vivienda (CORVI) (1972a). CORVI, en el centro de la producción. Revista Auca, 23, 40-67.

Corporación de la Vivienda (CORVI) (1972b). Tipologías de viviendas racionalizadas 1966-1972. Valparaíso: Subdepartamento de Diseño CORVI.

ESGUERRA, A. (2019). Future objects: tracing the socio-material politics of anticipation. Sustain Sci 14(4), 963-971. DOI: https://doi.org/10.1007/s11625-01900670-3

GALAZ MANDAKOVIC, D. (2019). Edificios máquinas: Arquitectura Moderna y disciplinaria del Frente Popular en Tocopilla. AUS [Arquitectura / Urbanismo / Sustentabilidad], (26), 29-34. DOI:10.4206/aus.2019.n26-06

GÁMEZ, V. (1999). Algunos antecedentes para el estudio de la doctrina habitacional de la Corporación de la Vivienda. Revista INVI, 14(38), 27-58.

HÖLSCHER, L. (2019). Future pasts: about a form of thought in modern society. Sustain Sci, 14(4), 899-904. DOI: https://doi.org/10.1007/s11625-019-00678-9

HUGHES,T. (1989). The Evolution of Large Technological Systems. En: Bijker, W., Hughes, T. y Pinch, T. (eds.), The Social Construction of Technological Systems (pp.51-82). Cambridge: MIT Press.

LAMPLAND, M. Y STAR, S. L. (eds.) (2009). Standards and Their Stories: How Quantifying, Classifying, and Formalizing Practices Shape Everyday Life. Cornell University Press.

LATOUR, B. (1987). Science in Action: How to Follow Scientists and Engineers Through Society. Cambridge: Harvard University Press

LAW, J. Y MOL, A. (2020). Words to think with: An introduction. The Sociological Review, 68(2), 263-282. DOI: https://doi.org/10.1177/0038026120905452

LE CORBUSIER (1953). El Modulor. Ensayo sobre una medida armónica a la escala humana aplicable universalmente a la arquitectura y a la mecánica. Buenos Aires: Editorial Poseidon.

MONEO, R. (1978). On typology. Oppositions, 13, 22-45.

MONEO, R. (2015). Typology in the context of three projects: San Sebastian, Lacua, Aranjuez. The Journal of Architecture, 20(6), 1067-1087. DOI: 10.1080/13602365.2015.1116347

Quiroga, H. (1972). Conclusiones. CORVI, en el centro de la producción. Revista Auca, (23), 64-65.

REDFIELD P. (2016). Fluid technologies: The Bush Pump, the LifeStraw and microworlds of humanitarian design. Social Studies of Science, 46(2), 159-183. DOI: https://doi.org/10.1177/0306312715620061

SEPÚLVEDA MELLADO, O., Y CARRASCO PÉREZ, G. (1991). Reflexiones en torno a la producción serializada de viviendas sociales en Chile. Revista INVI, 6(13-14), 23-34.

STAR, S.L. (2002). Got Infrastructure? How Standards, Categories and Other Aspects of Infrastructure Influence Communication. The 2nd Social Study of IT workshop at the LSE ICT and Globalization, 22-23 April.

VERGARA VIDAL, J. (2017). Verticalización. La edificación en altura en la Región Metropolitana de Santiago (1990-2014). Revista INVI, 32(90), 9-49. 